\title{
Bio-Virus Spread Simulation in Real 3D Space using Augmented Reality
}

Kostandinos Tsaramirsis, ${ }^{1}$ Akshet Patel, ${ }^{2}$ Pranav Sharma, ${ }^{2}$ Nikunj Reddy, ${ }^{2}$ Princy Randhawa,${ }^{2,}$ Georgios Tsaramirsis, ${ }^{3}$ Athanasia Pavlopoulou, ${ }^{4,5}$ Zeynep Ahsen Koçer ${ }^{4,5}$ and Dimitrios Piromalis ${ }^{6}$

\begin{abstract}
Due to the emergence of the novel human coronavirus disease (COVID-19), human life is jeopardized. Normal livelihood and economy have been disrupted due to safety concerns associated with the viral dissemination. The pandemic has instilled fear in people due to the lack of understanding and the impact an infection could have. In addition, laboratory experiments focused on coronavirus infection dynamics are labor intensive, costly and time consuming. A viable alternative to wet-lab experimentation is the in silico simulations, which enable difficult tasks to be efficiently and accurately performed by both professionals and citizens alike. This would enable people to gain a simpler understanding of the coronavirus dissemination and be informed timely, to take the preventive measures required. The application described herein was designed to simulate the spread of Covid-19 on different surfaces and showcase its longevity. A case study was also conducted by using this application.
\end{abstract}

Keywords: Augmented Reality; Virtual Reality; Covid-19; Simulator; Simulation; Virus Simulator; Unity3D.

Received: 18 October 2021; Accepted: 26 November 2021.

Article type: Research article.

\section{Introduction}

The growth of Augmented Reality and its reach among the global population has promoted innovation and creativity to recreate innumerable simulations related to different topics. COVID-19 is responsible for the ongoing pandemic due to its highly infectious nature, with over 18 million COVID-19 cases worldwide as of July 2021 as per the World Health Organization (WHO). ${ }^{[1]}$

Researchers all over the globe collaborate to safely experiment towards unraveling the mysteries of the

${ }^{1}$ Infosuccess3d, Aigaleo, Athens, 12242, Greece.

2 Department of Mechatronics Engineering, Manipal University Jaipur, Jaipur, Rajasthan, 303007, India.

${ }^{3}$ Department of Computer Science, Higher Colleges of Technology, Abu Dhabi, 51133, UAE.

${ }^{4}$ Izmir Biomedicine and Genome Center, Balcova, Izmir, 35340, Turkey.

${ }^{5}$ Izmir International Biomedicine and Genome Institute, Dokuz Eylul University, Balcova, Izmir, 35340, Turkey.

${ }^{6}$ Department of Industrial Design and Production Engineering, University of West Attica, P. Ralit and Thivon 250, Egaleo, 12244, Greece.

*Email: princy.randhawa@jaipur.manipal.edu (P. Randhawa) coronavirus, ranging from the sustenance of the virus in different mediums and temperatures in controlled environments, along with several simulation studies relating to the behavior and spread of COVID-19. ${ }^{[2,3]}$ This has been instrumental in allowing the common people, as well as researchers, to study the parameters actively and accurately over a huge global network, which has been elemental in controlling the spread of the current pandemic. ${ }^{[3]}$

The primary research conducted in these fields allowed the development of an ingenious method to simulate the spread of COVID-19 on various surfaces utilizing controlled infection. This was achieved through the augmented reality application, which displays the amount of time the virus can persist on the surface. The application is a safe tool for recognizing the means through which viruses spread through visual media; it aims at providing information and spreading awareness regarding the infectious nature of the virus. With the emergence of novel mutations of the coronavirus, there is a greater threat due to the higher transmission rates observed. This would have implications through the way the virus spreads, and represents a feature to add as a custom variable in the app. The application can simulate other infectious viruses on surfaces as well, and even after the pandemic is over, the application developed would still attain its purpose by 
serving as an education medium for many people, emulating the spread of a given virus.

COVID-19 is highly infectious, and can spread through direct, as well as indirect contact, across populations. Contaminated surfaces are one of the key means for the spread of the virus. Common contact points such as doorknobs or door handles are delicate contact focuses through which COVID-19 can spread among individuals. Fomite transmission of COVID-19 represents a genuine risk:;2] therefore, it is of paramount importance to have an understanding of the infectious nature of the virus, so as to contain its spread. Several studies have been conducted to perceive how long the COVID-19 virus particles can last on different materials. Based on which it was found that the life expectancy of the virus differs from surface to surface, depending on the composition and texture of the material. As per the research, COVID-19 is seen to remain viable on surfaces over several days and maintain its infectivity in the form of aerosols for hours. ${ }^{[3]}$ Numerous studies conducted have shown very comparable results regarding the virus's sustenance, further supporting the credibility of the findings. Table 1 formulates the data used in the application for the lifespan of Covid-9 applicable for temperatures greater than room temperature.

Temperature and humidity are parameters that affect the transmission rates of the virus. Results have shown that higher relative humidity/temperature reduce the spread. The replication values were seen to change with every percentage increase in both of the parameters. ${ }^{[4]}$ It was also seen that COVID-19 lived longer on impermeable surfaces more than permeable surfaces due to faster rates of evaporation that took place for permeable substances. ${ }^{[5]}$
It was also observed that COVID-19 remains extremely stable over a wide range of $\mathrm{pH}$ values $(\mathrm{pH} 3-10)$ at room temperature. However, there is not sufficient research regarding the sustenance of the virus on materials covering a wide range of temperatures. ${ }^{[6]}$ Therefore, the available findings were chosen based on their approximation to the room temperature; the upper limit of time-period of infectivity was selected for generic materials such as plastic and clothing.

However, it has been argued that COVID-19 can persist longer outside laboratory conditions, since virus experiments are usually conducted in controlled conditions which are unlikely to be mimicked in the real world. Hence, we could suggest that the data from the app are very reliable and safe for events replicated in real-world scenarios. Moreover, the coronavirus is not transmitted through the human skin; someone is only going to get infected if the virus comes in contact with his/her mouth, nose, or eyes.

It has been demonstrated that sunlight can inactivate COVID-19 on inanimate surfaces, indicating that parameters such as the sustenance of the virus would differ for indoor and outdoor conditions and also incline towards weather conditions. ${ }^{[7]}$ Fig. 1 describes the co-occurrences of keywords from the research papers compiled for Bibliometric analysis. As per another Ultraviolet-C (UV-C) research, the light was shown to be effective in inactivating COVID-19, but the amount of UV-C irradiation dose required varied according to the material. ${ }^{[8]}$

Unsuspected personnel are likely to be infected even if they successfully manage to avoid coming into contact with an infected surface, as coronavirus remains highly infectious in aerosol form for up to three hours, and respiratory droplets pose a very high risk for transmission among human beings.

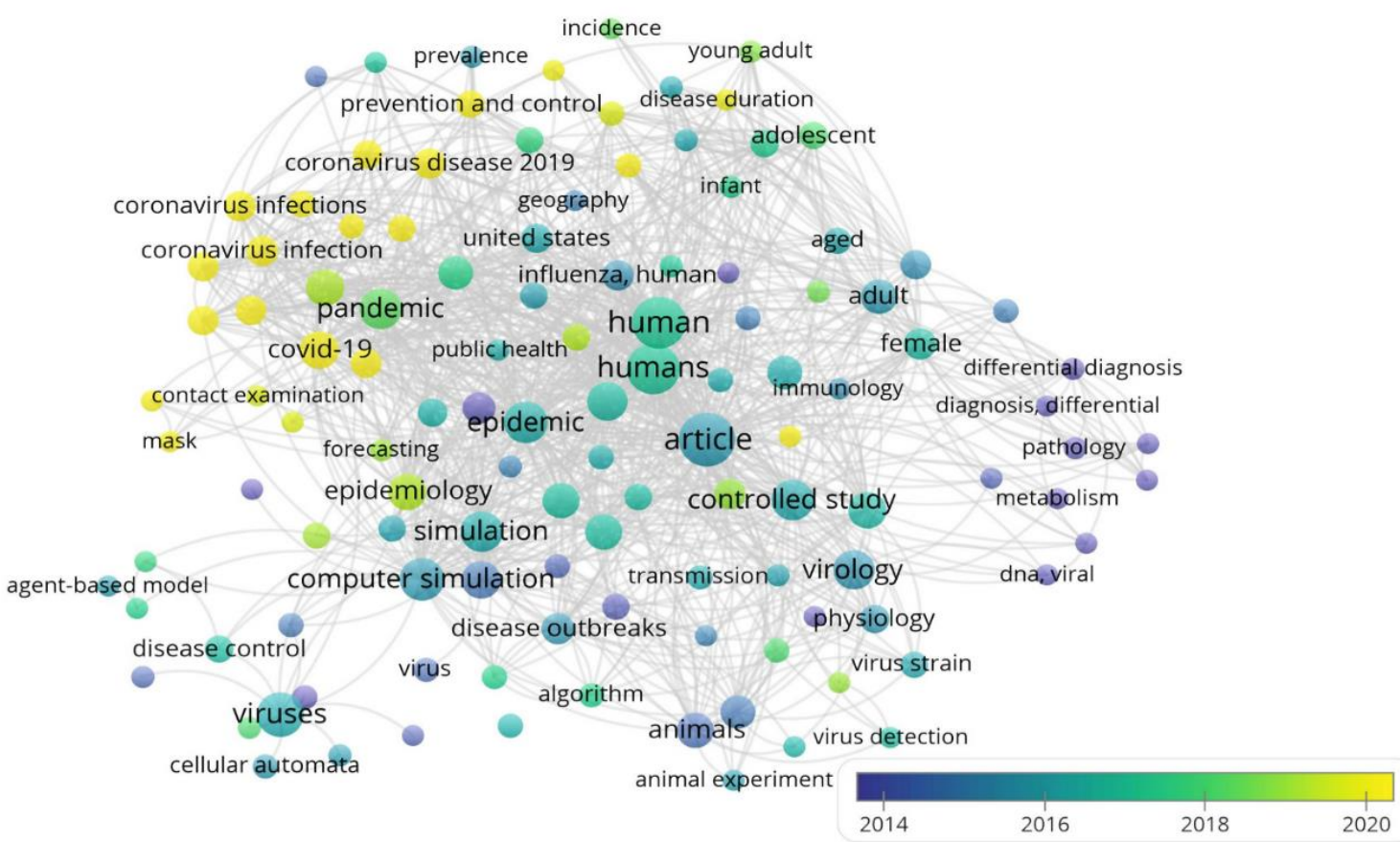

Fig. 1 Co-occurrences of keywords from the research papers compiled for Bibliometric analysis. 
Table 1. Data used in the application for the lifespan of Covid-9 applicable for temperatures greater than room temperature.

\begin{tabular}{|c|c|c|c|}
\hline Surfaces & Duration & Temperature/Humidity & References \\
\hline Cardboard & Up to 24 hours & 21 to $23{ }^{\circ} \mathrm{C}$ and $40 \%$ relative humidity & [9] \\
\hline \multirow[t]{2}{*}{ Stainless Steel } & 7 days & $22{ }^{\circ} \mathrm{C}, 65 \%$ humidity & {$[6]$} \\
\hline & 48 hours & 21 to $23{ }^{\circ} \mathrm{C}$ and $40 \%$ relative humidity & [9] \\
\hline Air & Up to 3 hours & 21 to $23{ }^{\circ} \mathrm{C}$ and $40 \%$ relative humidity & [9] \\
\hline Copper & Up to 4 hours & 21 to $23^{\circ} \mathrm{C}$ and $40 \%$ relative humidity & [9] \\
\hline Cloth & 2 days & $22{ }^{\circ} \mathrm{C}, 65 \%$ humidity & {$[6]$} \\
\hline Bank Note & 4 days & $22{ }^{\circ} \mathrm{C}, 65 \%$ humidity & {$[6]$} \\
\hline Glass & 4 days & $22{ }^{\circ} \mathrm{C}, 65 \%$ humidity & {$[6]$} \\
\hline Wood & 2 days & $22^{\circ} \mathrm{C}, 65 \%$ humidity & {$[6]$} \\
\hline Aluminum & 2-4 hours & N/A & {$[10]$} \\
\hline \multirow[t]{2}{*}{ Plastic } & 7 days & $22{ }^{\circ} \mathrm{C}, 65 \%$ humidity & {$[6]$} \\
\hline & 72 hours & 21 to $23{ }^{\circ} \mathrm{C}$ and $40 \%$ relative humidity & [9] \\
\hline Surgical Masks & 7 days & $22{ }^{\circ} \mathrm{C}, 65 \%$ humidity & {$[6]$} \\
\hline \multirow[t]{2}{*}{ Surgical glove } & 24-48 hours & $35^{\circ} \mathrm{C}, 20 \%$ humidity & {$[10]$} \\
\hline & 3-9 hours & $35^{\circ} \mathrm{C}, 60 \%$ humidity & \\
\hline $\begin{array}{l}\text { Printing and Tissue } \\
\text { Paper }\end{array}$ & 3 hours & $22^{\circ} \mathrm{C}, 65 \%$ humidity & [6] \\
\hline Ceramic & $>7$ days & $25-27^{\circ} \mathrm{C}, 35 \%$ humidity & {$[10]$} \\
\hline
\end{tabular}

\section{Background}

Novel and infectious viruses are emerging every year, and it has become of great importance to conduct proper surveillance of these viruses. Human factors such as the increasing population density, rise in travel and generated waste, as well as climate changes due to increase in the carbon footprint causing global warming, has a direct effect on the emergence of new viruses leading to epidemics and pandemics. ${ }^{[1]}$

The Eclipse Foundation supports an open-source softwarebased project called project Spatiotemporal Epidemiological Modeler (STEM) which is used at a global level by researchers and health officials for tracking and controlling infectious virus outbreaks among humans as well as animals. ${ }^{[12]}$ STEM is not used for modelling purposes, but it has many reusable plugins and data with frameworks that can be used for multiple viruses.

The mode through which the viral infection takes place can be estimated by solely analyzing the virus-infected cell cultures and through live images of these cells. To compute this process, a framework which is called "Infectio" was developed which was used to simulate the infection directly in tissue cultures which makes it possible to simulate virtually any virus. ${ }^{[13]}$

There are several online tools which are developed to simulate the spread of a custom virus in case of an epidemic or a pandemic. An example of one such tool is "Virus outbreak simulator"'[14] which allows the researcher, or the user to select a virus, input the varying parameters, and compute the spread of the virus based on intelligent algorithms. The parameters of a custom virus can also be used as an input to check out the probability of the spread of that virus. Graphs can be plotted, and thus the number of the people sick, infected, recovered, and immune to a virus can be estimated.

In order to predict the immunity of an individual against a virus, tools based on the "Gillespie" algorithm have been developed for the same purpose. ${ }^{[15]}$ The models are built so that the spread of the virus can be visualized and analyzed in a confined space.

Prediction algorithms such as "Gaussian Curve Fittings" are used to predict the number of infections of the coronavirus 
in the future months based on the trends of the virus spread and the data collected ${ }^{[16]}$ Methods such as linear regression, simple time series prediction, Markovian-based methods are also used in this kind of modeling.

Mathematical models based on susceptible, infected and recovered (SIR) models can estimate the number of people which could get infected and the number of infections at any given time ' $t$ ' and the rate of change of them concerning time and their sum. ${ }^{[17]}$

The research efforts of Khan and Atangana (2020) and their attempt to model the spread of the coronavirus using fractional derivate produced graphical results of the spread which can be very useful for tracking the infection rate. ${ }^{[18]}$ This led to the development of a numerical stability model by Singh and colleagues ${ }^{[19]}$ in which they successfully studied and modelled the fractional-order dynamics of COVID-19 virus spread. They used nonlinear equations which include parameters like susceptible people, exposure rate, infected people, number of people recovered and virus removal rates.

CovidSim ${ }^{[20]}$ is another such tool to predict the number of cases, recovery rate and future analysis of the spread of coronavirus in any country based on many input parameters. The input parameters include population, infection rate and probability, duration of the infection, age of the patient, hospitalization rate and detection rate. This tool was developed by Markus and Martin and their project was supported by the Investigation \& Mathematical Analysis of Avant-garde Disease Control (IMAAC) association and the University of Tubingen. ${ }^{[20]}$

The researchers at Boston (WHDH), Finland, developed a simulator in $3 \mathrm{D}$, which can simulate the spread of the coronavirus in a supermarket by just a single cough. A cough is a form of aerosol, and this principle is used in simulation studies where the cough can travel through ventilation ducts and air conditioner ducts and spread throughout the entire store. This study proves how dangerous a single cough of an infected person can be and how it can spread in an entire supermarket. This research should be taken into consideration in order to avoid visiting public places in case of a pandemic outbreak. ${ }^{[21]}$

Studies and development conducted at the University of Bogota have resulted in the design of a simulator called "INFEKTA" which uses different computational and mathematical algorithmic models to simulate the transmission of the coronavirus in a closed space (Euclidean space). ${ }^{[22-23]}$

Computing simulators developed by the researchers at the University Abdelmalek Essadi (Morocco) based on Agentbased modeling, also known as the ABM, have sued the angular frameworks, Perlin noise algorithm and QuadTree algorithm to simulate the spread of the coronavirus in a closed space based on parameters like the density of the crowd, as well as the number of people and the ratio of the infected to uninfected people. The simulator runs by depicting different color-coded circles on the screen such as red for infection, green for healthy and blue for wearing a mask.
MD Corona ${ }^{[24]}$ is a simple simulator that can analyze the infection dynamics of the coronavirus and it takes into consideration three parameters, namely, the density of the population, the rate of socially isolated people and the probability of transmission of the virus. This model of simulation also considers other parameters involving epidemiology. The calibration of the model is done using the surveys conducted to measure the rate of immunity, and it can also provide accurate transmission probability and rates using different spread analyzing mechanisms. ${ }^{[24]}$

The Corona-land simulator was developed for the purpose of observing and learning the spread and effect of the coronavirus. The simulator has several parameters like the rate of population, infection rate, number of Intensive Care Unit (ICU) beds and the number of people wearing a mask. The result of this simulator is graphs and predictions to show the number of people getting infected or at fatal risk. ${ }^{[25]}$

Many computational simulation models have been designed and developed by researchers all around the globe to tackle the coronavirus crisis. These models include simulators tracking the spread of the virus in a closed space and the transmission dynamics of the virus by taking various input parameters into account. ${ }^{[26]}$

\section{Methodology}

The methodology followed for building and developing the application involved two major processes, the first one being the entire construction viz. entire methodology, various tools and software used to build and test the application, while the second part covers the in-depth working and the step-by-step usage of the application. ${ }^{[30]}$

The sole purpose of the application is its ability to simulate the spread of various viruses in the real world using augmented reality. The application was developed using Unity-3D, a cross-platform game engine that enables users to build various apps using the in-built functionality of the software, without having to code everything from scratch. There are various other gaming engines available in the market, such as the "Unreal Engine", but their high sophistication complicates its usage. ${ }^{[31]}$ Unity3D allows a perfect balance between sophistication and ease of use, making it an ideal software for use in our case. ${ }^{[32]}$

$\mathrm{C} \#$ was used to program the application, and 3D graphic design software such as Blender and 3D Builder were employed to import the required 3D objects such as the virus models into Unity. ${ }^{[33]}$ Google's Extended Reality (XR) support was used to continuously test the application. The summary of the tools and simulators developed to analyze the spread of COVID-19 virus has been summarized in Table 2.

\subsection{Steps to use the augmented reality (AR) virus app simulator}

The flowchart for operating the AR application has been described in Fig. 2.

i. Entering the Temperature into the dialog box: 
Table 2. Summary of the tools and simulators developed to analyze the spread of COVID-19 virus.

\begin{tabular}{|c|c|c|c|}
\hline Name of the Simulator/ Algorithm & Type of Simulator & Input parameters & Output \\
\hline $\begin{array}{l}\text { Spatiotemporal Epidemiologic } \\
\text { Modeler (STEM) }\end{array}$ & Modelling of the virus & $\begin{array}{l}\text { Population, infected people, rate of } \\
\text { transmission }\end{array}$ & $\begin{array}{l}\text { Analyzed reports of the } \\
\text { spread of the virus }\end{array}$ \\
\hline Infectio $^{[28]}$ & $\begin{array}{l}\text { Infection simulator } \\
\text { within the cell }\end{array}$ & Images of the cell, RNA of the virus & $\begin{array}{l}\text { Simulate the } \\
\text { transmission within the } \\
\text { tissue }\end{array}$ \\
\hline Virus Outbreak Simulator ${ }^{[29]}$ & Virus Spread Simulator & $\begin{array}{l}\text { Population, infected people, rate of } \\
\text { transmission }\end{array}$ & $\begin{array}{l}2 \mathrm{D} \text { design of the spread } \\
\text { in space }\end{array}$ \\
\hline Gillespie Algorithm $^{[15]}$ & $\begin{array}{l}\text { Prediction of the rate of } \\
\text { transmission }\end{array}$ & $\begin{array}{l}\text { Infected people, isolated people, } \\
\text { population }\end{array}$ & Graphs, charts \\
\hline Gaussian Curve Fittings $^{[16]}$ & $\begin{array}{l}\text { Prediction of the rate of } \\
\text { transmission }\end{array}$ & $\begin{array}{l}\text { Infected people, isolated people, } \\
\text { population }\end{array}$ & Graphs, charts \\
\hline SIR Models ${ }^{[17]}$ & Modelling of the virus & $\begin{array}{l}\text { Population, infected people, rate of } \\
\text { transmission }\end{array}$ & $\begin{array}{l}\text { Simulate the viral } \\
\text { transmission in } 3 \mathrm{D} \\
\text { space }\end{array}$ \\
\hline CovidSim $^{[18]}$ & $\begin{array}{l}\text { Prediction of the rate of } \\
\text { transmission }\end{array}$ & $\begin{array}{l}\text { Infected people, isolated people, } \\
\text { population }\end{array}$ & $\begin{array}{l}\text { Graphs, charts, } \\
\text { animation }\end{array}$ \\
\hline INFEKTA $^{[19]}$ & Virus Spread Simulator & $\begin{array}{l}\text { Population, infected people, rate of } \\
\text { transmission }\end{array}$ & $\begin{array}{l}\text { Animation of viral } \\
\text { infection in space }\end{array}$ \\
\hline Agent-Based Modelling ${ }^{[20]}$ & $\begin{array}{l}\text { Prediction of the rate of } \\
\text { transmission }\end{array}$ & $\begin{array}{l}\text { Infected people, isolated people, } \\
\text { population }\end{array}$ & Graphs, charts \\
\hline MD Corona ${ }^{[24]}$ & Virus Spread Simulator & $\begin{array}{l}\text { Population, infected people, rate of } \\
\text { transmission }\end{array}$ & $\begin{array}{l}\text { Animation of viral } \\
\text { infection in space }\end{array}$ \\
\hline Corona-land $^{[25]}$ & $\begin{array}{l}\text { Virus Spread Simulator } \\
\& \text { Prediction of the rate } \\
\text { of transmission }\end{array}$ & $\begin{array}{l}\text { Population, infected people, rate of } \\
\text { transmission }\end{array}$ & $\begin{array}{l}\text { Animation of viral } \\
\text { infection in space }\end{array}$ \\
\hline $\begin{array}{l}\text { Transmission } \\
\text { simulator }^{[26]}\end{array}$ & $\begin{array}{l}\text { Prediction of the rate of } \\
\text { transmission }\end{array}$ & $\begin{array}{l}\text { Infected people, isolated people, } \\
\text { population }\end{array}$ & Graphs, charts \\
\hline Numerical Stability Model ${ }^{[16]}$ & Virus Spread Simulator & $\begin{array}{l}\text { Population, infected people, rate of } \\
\text { transmission }\end{array}$ & $\begin{array}{l}\text { Animation of viral } \\
\text { infection in space }\end{array}$ \\
\hline Markovian-based Method ${ }^{[15]}$ & Virus Spread Simulator & $\begin{array}{l}\text { Population, infected people, rate of } \\
\text { transmission }\end{array}$ & $\begin{array}{l}\text { Animation of viral } \\
\text { infection in space }\end{array}$ \\
\hline
\end{tabular}

Upon opening the application, a dialog box appears on the screen where the user must enter the current surrounding temperature in which s/he wants to simulate the spread of the virus. Various studies show that the sustainability of a virus on a surface is directly linked to room temperature. A temperature panel is provided in the application, to emulate the survival of viruses on different surfaces, considering the surrounding temperature.

\section{ii. Home Screen appears:}

As soon as the temperature is entered, a home screen appears, where the user sees the entered temperature on the top right corner of the screen. Additionally, the buttons are visible on the home screen that are essential for the simulation of the viruses.

iii. Selecting the Material:

The initial step of the simulation would be to select the virus and the material on which the sustenance of the virus is to be simulated. This can be done by clicking on the Menu button, present on the top left of the screen. This opens a new window, showing a list of all the materials that have been stored within 


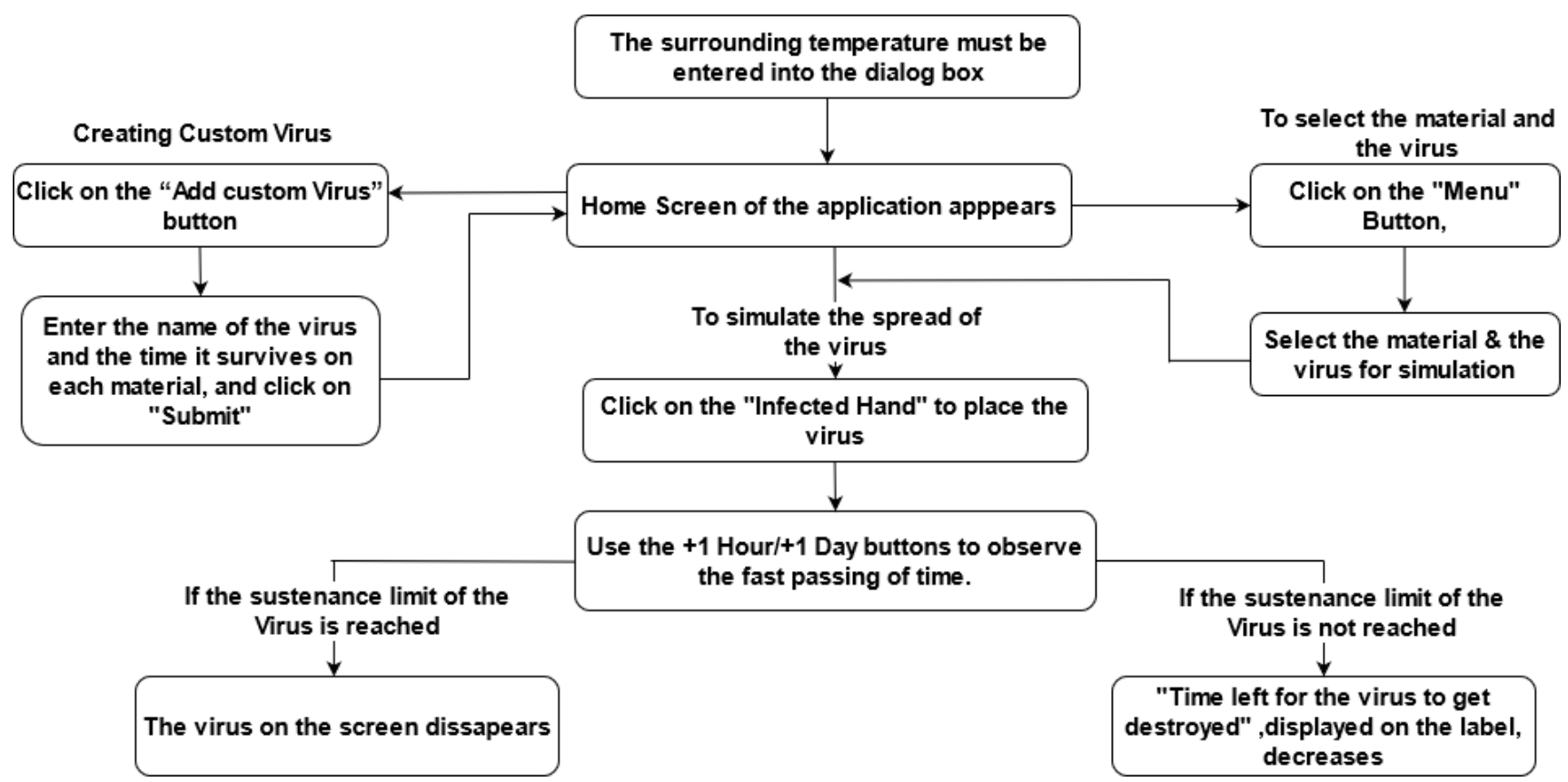

Fig. 2 Flowchart for operating the AR application.

the app. A few materials included are cloth, paper, plastic, etc. The user can select any of these surfaces to simulate the spread of the virus.

iv. Selecting the Virus:

After choosing the material, the user further needs to choose the virus the spread of which needs to be simulated. Initially, the app only consists of 'Coronavirus', also offering the option to add a custom virus. Once the user has selected the material and the virus, $\mathrm{s} / \mathrm{he}$ can exit this panel by simply clicking on the 'return' button and return to the home page.

v. Creating the custom virus:

To create a custom virus, the user would have to return to the home screen and click on the "Add custom Virus" button, which will open a form where the user would have to fill in the name of the virus, and the time it lasts on different surfaces and click on submit to store the data. The time of survival of the virus on all the materials must be entered, and no field must remain blank for the custom virus to be created.

vi. Simulating the spread of the virus:

The user can view a hand on the screen with the label of "Infected Hand" on it; this acts as a medium for the virus to spread. The virus can be transmitted in the user's real environment by tapping on the hand. The virus appears on the screen with a label on top of it that includes information about the "Time left for the virus to get destroyed", "Name of Virus", "The material on which the virus is placed" and "The total life of the virus". The user can toggle between the visibility of the panel using the 'Hide \& Show Panel' buttons situated on the home screen. Once the virus is transmitted into the virtual world of the application, the location and position of the virus get recorded, which does not change even with the movement of the phone.

vii. Controlling the passing of time within the application:

The essential part of simulation in the application is control of time, for which two buttons are provided "+1 Hour" and "+1 Day", where pressing "+1 Hour" will add an hour in the application and pressing "+1 Day" will add a day, respectively. As the user presses any of these buttons, the time within the application passes and "Time left for the virus to get destroyed", displayed on the label, decreases. Once the time for the virus to get destroyed elapses, the virus would no longer be visible on the screen. The user can always tap on the hand once again to create a new virus and repeat the same process with other viruses, and other surfaces.

\section{Case study (using the developed simulation tool in real- time in a super market)}

By using the AR application, we performed a simulation on the spread of the coronavirus and a custom virus in a local supermarket. The User Interface of the application being tested in a Supermarket and the User interface of the application demonstrating the selection of the material and the virus has been depicted in Fig. 3 and Fig. 4. This was done to correctly comprehend the general use case where our application would be used and whether it fulfils its objective. The operation, ease of usage and functionality of the app were considered after a short survey was conducted among the people who were present in the shop. A short demonstration was performed before individual participants of the survey experimented with the app. The information relayed is as follows-Upon opening the app, firstly we entered the correct room temperature into the dialog box that appeared on the screen and clicked on "Confirm". A home screen appeared, where we could view the entered room temperature on the top right of the screen along 
with various other buttons that are essential in the operability of the application. ${ }^{[34]}$

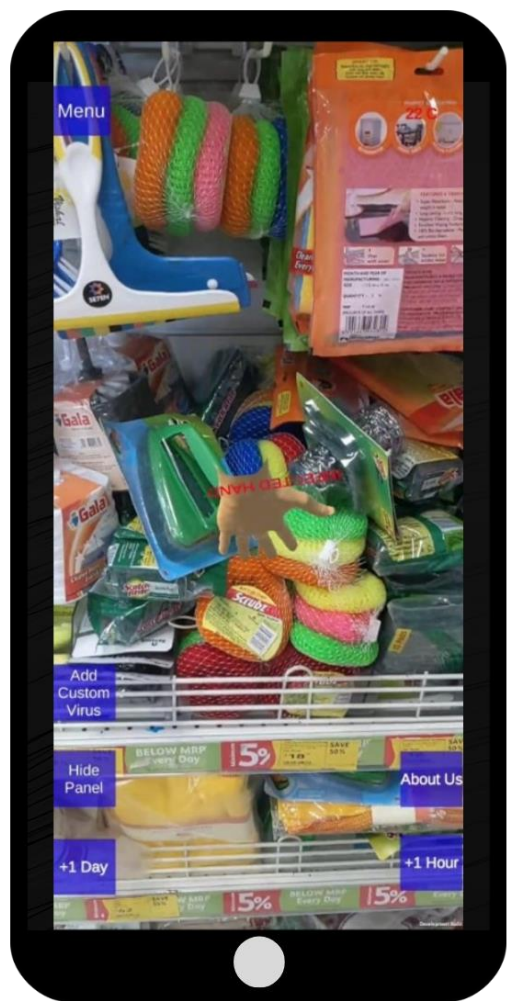

Fig. 3 User Interface of the application being tested in a Supermarket.

To start the simulation, the material for which the sustenance of the coronavirus is to be simulated needs to be simulated. This was achieved by clicking on the "Menu" button present on the home screen, which displays a list of materials that can be used for simulation. In our case we chose "Plastic" as the material for simulation, to demonstrate the spread of the coronavirus on the plastic fabric conditioner bottles that were placed in a certain section of the supermarket. After selecting the material, the application displays two further options for choosing the virus that needs to be simulated; we selected the "CORONA" virus. ${ }^{[35]}$

We return to the home screen by tapping on the "return" button that is present on the top right of the screen. This brings us back to the home screen, where we now view a hand on the screen with the label "Infected Hand". This essentially acts as a medium for the virus to spread. To transmit the virus within the application, we simply tap on the hand. The coronavirus is now displayed on the screen along with a label on top, which displays additional information such as the "Name of Virus", "Lifespan of the virus", "Surface Material" and the "Time Left for survival". In our case, the label displayed the Name 'Coronavirus', the material as 'plastic' and a total Lifespan of the virus as 5 days. We can switch between the visibility and disappearance of the label using the "Show Panel" and "Hide Panel" buttons that are situated on the home screen. ${ }^{[36]} \mathrm{We}$ make use of two buttons "+1 Day" and "+1 Hour" to observe the rapid passing of time within the application. On pressing any of these buttons the time within the application passed accordingly, and once the sustenance of the coronavirus on plastic was reached (in our case 5 days), the virus disappeared from the screen.

Similarly, we performed the simulation by placing a custom virus onto plastic. For this, we had to create a custom virus by clicking on the "Add Custom Virus" button present on the home screen. This opened a form where we added the "Name of the Virus" and its duration of survival on each of the 15 materials for which the sustenance of virus can be simulated, and then clicked on "Submit". Furthermore, iterating the process we used to transmit the coronavirus, we clicked on the "Menu" button and selected "Plastic" as the material, but this time we chose the "Custom" virus to be simulated. ${ }^{[37]}$

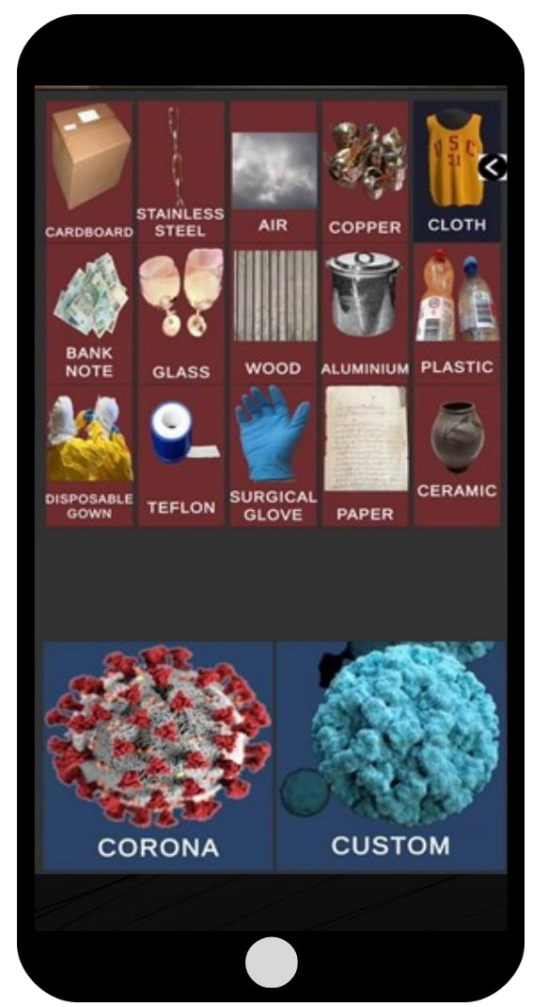

Fig. 4 User interface of the application demonstrating the selection of the material and the virus.

The same process was repeated to transmit the virus using the infected hand displayed on the screen; this time the label on the virus displayed the name a "Custom1", that is, the name we had entered while creating the custom virus.

As shown in Fig. 5, the "AR Virus App Simulator" is used in a residential kitchen and the position, and time left of the coronavirus can be observed. The material of the transmitted virus is selected from the app as "Ceramic" and the virus is spread on the marble of the kitchen working floor. The remaining time of the marble is displayed in the information panel. The simulated spread of the virus on the handles made of plastic can be observed in the same figure. Since the virus can remain alive for about 72 hours on a plastic surface, the timer can record 72 hours. It can be clearly observed that even 


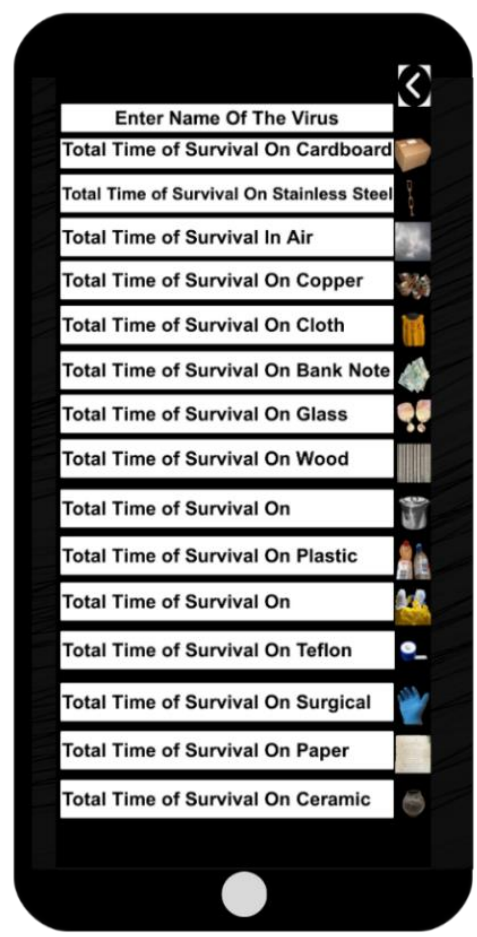

(a)

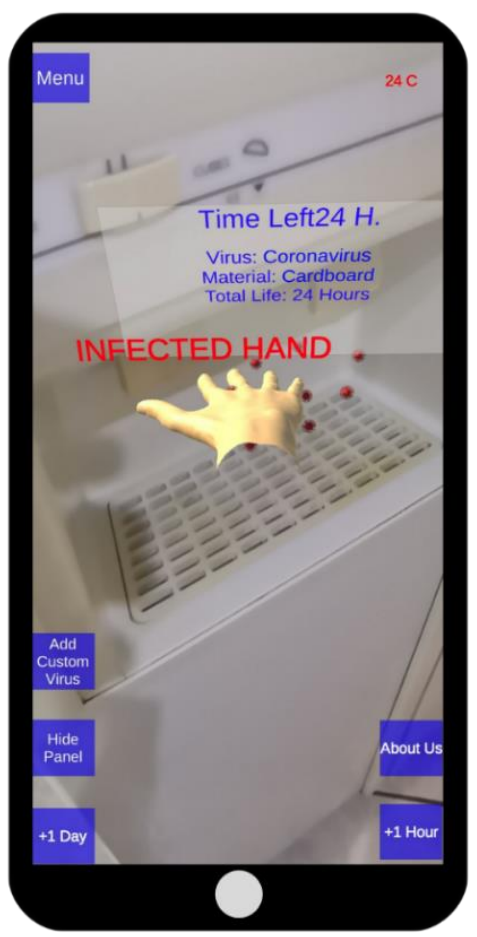

(b)

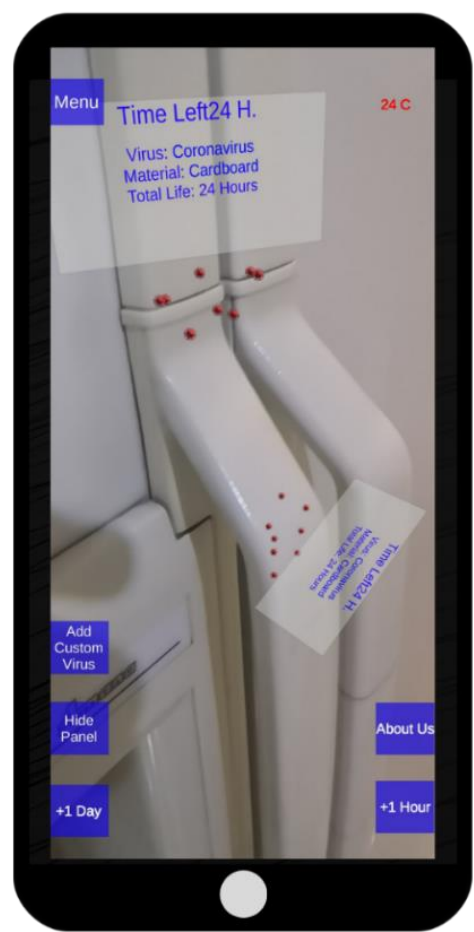

(c)

Fig. 5 Demonstration of the application: (a) customizing the custom virus (b) deploying the virus in the real world (c) virus deployed in augmented reality with information panel.

after the camera is pointed in another direction, the position and placement of the virus stays intact and does not disappear. An important feature of the app that was highlighted during this simulation was its ability to store the position at which the virus had been transmitted and display the virus at the same position even after the camera was moved away. This was tested by transmitting the virus at a particular spot, then moving the camera away, pointing at a different location. Now, the camera was pointed back to the initial location, and the virus was present at the same spot as it was initially.

After the experiment was conducted, a sample set of store employees and consumers were selected for the case study. After a quick demonstration, they used the application as per their buying needs or store specific requirements. Custom virus prefab was tested by some depending on their predisposition to different infectious media. The cleaning personnel of the marketplace were also involved in the examination of the spread and retention of the different viruses instigated over frequented surfaces. ${ }^{[38]}$

Based on the results of the survey, the application left a deep impression on the participants after witnessing first-hand the transmissibility of the virus. Most of them were warier about handling store products when not required and carrying out basic COVID-19 virus precautionary norms such as sanitizing hands or wearing masks. People of different domains took note of the activity in a way they could best prevent further infectivity of the virus; for reference the janitor gained additional knowledge regarding his obligations. The Survey had a broader impact on getting the attention of young children, as this new interactive and visual media allowed them to gain further understanding. Of particular note, every participant was able to simulate the virus particles. Feedback was received after experimentation with the app which allowed us to make further improvements, particularly with the User Interface. ${ }^{[39]}$

\subsection{Applications of augmented reality application}

It can be used to simulate the spread of COVID-19 virus in any public space such as a marketplace, where the store owners can use it to visualize the surfaces which are infected. As the application stores the location of the virus-laden object, users can recheck the application to be informed about the sustenance of the virus later of the day, and accordingly, take the necessary precautions over the high contact points once they estimate the viability of the virus on different surfaces in each area.

The application also serves a role on the educational forefront, as it sets up a platform to interact with the infectious nature of the coronavirus in an easy and harmless way. The visual depiction of the severity of the spread of this virus would ascertain that children or uninformed individual approach their surroundings and external contact points with added precaution, thereby preventing possible infections.

The ability to add custom virus variables allows to demonstrate its applicability to similar infectious viruses, with the flexibility to include newer research findings.

\section{Results}

The results were obtained after several developments were made within the application, which was later tested on various 
mobile devices using the Google XR support. The application successfully simulates the spread of COVID-19 virus on direct contact and exhibits the virus' properties based on the material of the infected object. Moreover, the data about the remaining life expectancy of the virus were displayed along with additional data. The application also provides a feature to manually skip forward through the time periods. The ability to create and simulate the custom virus proved to work as well as in the case of the coronavirus. The short survey findings shed more light on the coronavirus spread and could lay the foundation for future endeavors that would improve the functioning of the application. People from different domains were able to make use of the application with ease and in a short time, because of app's simple handling and its ingenious nature. The main goal and sequential objective of this application were adequately met, including the heightened awareness and inclination to prevent further spread or avoid infection with the virus.

\section{Future scope}

The simulation app has high potential through means of its application, by incorporating more defining parameters and variables, which would aid in performing the simulation with very high accuracy. This includes accounting for weather conditions, humidity, or temperature for the sustenance periods of the virus. Research studies have demonstrated how the artificially controlled lab conditions provide results that are different when compared to actual survival time. Sunlight, UV-C, and control inputs from outdoor or indoor environments can provide better results. Material type such as smooth rough permeable, impermeable etc., also affect the overall survival of the virus.

Disinfectants have proven to greatly reduce coronavirus survival times to under 1 hour in several materials; therefore, the simulation would be able to showcase this element as well. At last, significant research findings and equations are of high importance for these changes to become reflected on the app, even for custom variables that would work for a massive range of infectious viruses.

\section{Limitations}

One drawback of the application is the inferior smartphone cameras which are incapable of properly perceiving depth which has, as a result, our indicator/infected object to misrepresent the plane or surface and place objects incorrectly. However, this condition is well avoided based on requirements as if when tables or shelves are conserved, due to the presence of a well-defined plane such as the shelves in a supermarket. Nevertheless, with further research and additional findings, additional information will be acquired about the sustenance of COVID-19 virus on diverse materials, taking into consideration the temperature, as well as more properties of the coronavirus.

\section{Conclusion}

This paper presents several studies on the simulation practices that are used to visualize and analyze the spread of the coronavirus or any other custom virus in real-time in $3 \mathrm{D}$ space. Our application can be used to simulate the spread of COVID19 virus and any other custom-selected strains of the coronavirus. The simulator efficiently allows the user to analyze the spread of the virus depending on the environmental conditions which directly impact the sustenance of the virus on a particular material.

The fact that the coronavirus can remain viable on different surfaces for days is a genuine risk, but this is not the only cause for the spread of this virus among humans. All the necessary precautions put in place such as wearing masks must be upheld, as COVID-19 virus can remain viable via airborne droplets and particles and so can infect people. The simulation application described herein aims to provide an understanding of the infective nature of the virus which persists on several surfaces and raise awareness supported with research data. Virtual reality (VR) and augmented reality (AR), two modern simulation models, are presently being used to improve medical education. VR offers users a 3D and dynamic perspective of structures, as well as the ability to interact with them. VR is ideal for training in practical learning operations because of current technical developments in haptics, touch screen, and motion recognition, which allows a user to have an authentic and engaging experience. AR allows to project digital environments and structures onto real-world objects, augmenting or changing the environment. Therefore, the usage of AR apps to better comprehend anatomy and biological functions is particularly useful.

\section{Conflict of interest}

There are no conflicts to declare.

\section{Supporting information}

Not applicable.

\section{References}

[1] WHO Coronavirus (COVID-19) Dashboard | WHO Coronavirus (COVID-19) Dashboard With Vaccination Data [Internet]. [cited 2021 Nov 26];Available from: https://covid19.who.int/.

[2] M Colaneri, E Seminari, S Novati, E Asperges, S Biscarini, A Piralla, E Percivalle, I Cassaniti, F Baldanti, R Bruno, M U Mondelli, Clin. Microbiol. Infec., 2020, 26, 1094.e1-1094.e5.

[3] Y C Wu, C S Chen, Y J Chan, J. Chin. Med. Assoc., 2020, 83, 583.

[4] J Wang, K Tang, K Feng, X Lin, W Lv, K Chen, f. Wang, Impact of temperature and relative humidity on the transmission of COVID-19: A modelling study in China and the United States. BMJ Open, 2021, 11, e043863.

[5] S Chatterjee, J S Murallidharan, AAgrawal, R Bhardwaj, Phys. 
Fluids, 2021, 33, 021701

[6] AWH Chin, JTS Chu, MRA Perera, KPY Hui, H L Yen, MCW Chan, M Peiris, L L M Poon, Ann. Oncol., 2020, 1, e10.

[7] S Ratnesar-Shumate, G. Williams, B Green, M Krause, B Holland, S Wood, J. Bohannon, J. Boydston, D. Freeburger, I. Hooper, K. Beck, J. Yeager, L A Altamura, J Biryukov, J. Yolitz, M Schuit, V Wahl, M Hevey, P Dabisch, J. Infect. Dis., 2020, 222, 214-22.

[8] A Gidari, S Sabbatini, S Bastianelli, S Pierucci, C Busti, D Bartolini, A M Stabile, C Monari, F Galli, M Rende, G Cruciani, D Francisci, Viruses, 2021, 13, 2-9.

[9] D Taylor, A C Lindsay, J P Halcox, New Engl. J. Med., 2020, 0383, 2103-2105.

[10] M Bueckert, R Gupta, A Gupta, M Garg, A Mazumder, Materials, 2020, 13, 5211.

[11] E Christaki, New technologies in predicting, preventing and controlling emerging infectious diseases. 2015.

[12] J V Douglas, S Bianco, S Edlund, T Engelhardt, M Filter, T Günther T, K H Maggie, E J Nixon, N L Sevilla, A Swaid, J H Kaufman, Health Secur., 2019, 17, 291-306.

[13] A Yakimovich, Y Yakimovich, M Schmid, J Mercer, I F Sbalzarini, U F Greber, mBio, 2016, 7, e02164.

[14] Virus Outbreak Simulator [Internet]. [cited 2021 Jun 19], Available from: https://bioinformaticshome.com/online_software /virus-outbreak/US/index.html\#.

[15] Z Yan, Y Lan, Nonlinear Dynam., 2020, 101, 1643-51.

[16] A B Hassanat, S Mnasri, M Aseeri, K Alhazmi, O Cheikhrouhou, G Altarawneh, M. Alrashidi, A S Tarawneh, K S Almohammadi and H Almoamari, Sustainability, 2021, 13, 4888. [17] B Ivorra, M R Ferrández, M Vela-pérez M, Ramos AM. Mathematical modeling of the spread of the coronavirus disease 2019 (COVID-19) taking into account the undetected infections. The case of China. 2020, (January).

[18] M A Khan, A Atangana, Alex. Eng. J., 2020, 59, 2379-89.

[19] H Singh, H M Srivastava, Z Hammouch, K Sooppy Nisar, Results Phys, 2021, 20, 103722.

[20] CovidSIM [Internet]. [cited 2021 Jun 27];Available from: http://covidsim.eu/.

[21] 3D simulation shows how a single cough can spread coronavirus through a grocery store - Boston News, Weather, Sports | WHDH 7News [Internet]. [cited 2021 Jun 28];Available from: https://whdh.com/coronavirus/3d-simulation-shows-howa-single-cough-can-spread-coronavirus-through-a-grocerystore/.

[22] COVID-19 and Simulation - AnyLogic Simulation Software [Internet]. [cited 2021 Jun 19];Available from: https:/www.anylogic.com/blog/covid-19-and-simulation/.

[23] J Gomez, J Prieto, E Leon, A Rodríguez, PLoS One, 2021, $16,1-15$.
[24] D Maritza, S A Angel, multiagent coronavirus model with territorial vulnerability parameters, 2020, 1-27.

[25] Coronavirus simulator [Internet]. [cited 2021 Jul 8], Available from: https://corona-land.org/.

[26] H B Sezer, I K Namukasa, Int. J. Innov. Res. Sci. Eng. Technol., 2021, 14, 46-64.

[27] H H Thulke, L Tischendorf, C Staubach, T Selhorst, F Jeltsch, T Müller, H Schlüter, C Wissel, Prev. Vet. Med., 2000, 47, $1-21$.

[28] W Zhe, N Amit, H Xiaozhou, H Rui, D Pei, Agrofor. Syst., 2021, 3, 4-16.

[29] ]J. Zhao, S. Tang, J. Storhoff, S. Marla, Y. P. Bao, X. Wang, E. Y. Wong, V. Ragupathy, Z. Ye and I. K. Hewlett, BMC Biotechnol., 2010, 10, 16-19.

[30] O Y Burov, A E Kiv, S O Semerikov, A M Striuk, M I Striuk, L S Kolgatina, I V Oliinyk, AREdu 2020 - How augmented reality helps during the coronavirus pandemic, 2020.

[31] Using an AR Simulation for Hospital Spill Cleanup Training in Highly-Infectious Disease Holding Units. 2018, 1-11.

[32] A Asadzadeh, T Samad-Soltani, P Rezaei-Hachesu, Informatics Med Unlocked, 2021, 24, 100579.

[33] Perkins Coie LLP. 2020 Augmented and Virtual Reality survey report: Industry insights into the future of immersive technology. 2020, 4, 3-33.

[34] FAR Ekmeil, MSS Abumandil, M I Alkhawaja, I M Siam, SAA Alaklouk, J. Phys. Conf Ser., 2021, 1860.

[35] J Radianti, T A Majchrzak, J Fromm, I A Wohlgenannt, Comput, Educ., 2020, 147, 103778.

[36] K T Huang, C Ball, J Francis, R Ratan, J Boumis, J Fordham Cyberpsych. Beh. Soc. Net., 2019, 22, 105-10.

[37] B A Kuehn, J. Am. Med. Assoc., 2018, 319, 756-8.

[38] Kwok AOJ, Koh SGM. COVID-19 and Extended Reality (XR). Curr. Issues Tour., 2021, 24, 1935-40.

[39] C. Escadafal, J. T. Paweska, A. Grobbelaar, C. le Roux, M. Bouloy, P. Patel, A. Teichmann, O. Donoso-Mantke and M. Niedrig, PLoS Negl. Trop. Dis., 2013, 7, 1-7.

\section{Author information}

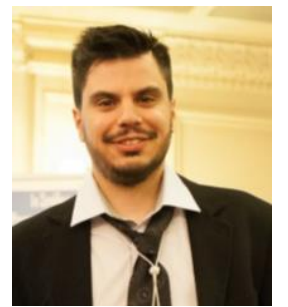

Kostandinos Tsaramirsis is the founder and CEO of infosuccess3D, Athens, Greece a $3 D$ content development company that has released several $3 D$ games, Virtual Reality and Augmented Reality Applications. Among the most popular is titles is Seed of the Arcane and Shades of heroes. Kostas received his BSc in Computer Science from Royal Holloway, University of London, UK, and his MSc in applied informatics from University of Reading, $U K$. 


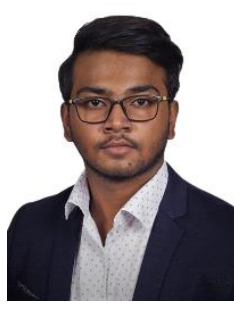

Akshet Patel is a Mechatronics Engineering student at Manipal University Jaipur. His research areas include Robotics, Augmented and Virtual Reality, Internet of Things (IoT).

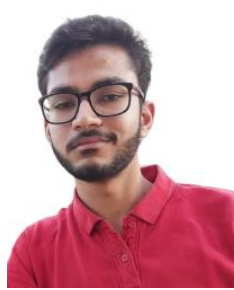

Pranav Sharma is a final year mechatronics engineering student at Manipal University Jaipur. His research areas include robotics and automation and intends to pursue his masters in the same field.

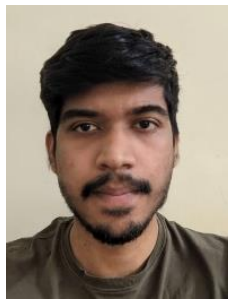

Nikunj Reddy is an undergraduate student from Manipal University Jaipur, who has completed his bachelor's education in mechatronics engineering. He is currently working at Accenture as a Full Stack Developers and intends to pursue Masters in Robotics to pursue key fields of his interest such as robotic application and automation.

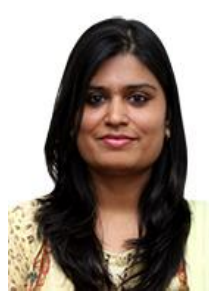

Princy Randhawa is currently working as an Assistant professor at Manipal University Jaipur, in the past she has worked as an Assistant Professor at MBSCET at Jammu; She completed her PhD in 2021 from Manipal University Jaipur, India in Machine Learning in Wearable Technology. Her fields of interest lie in research topics like Control Systems, Machine learning.

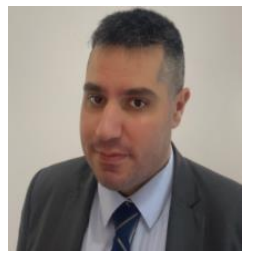

Georgios Tsaramirsis is an academic working as a full time faculty at higher colleges of technologies (HCT), Abu Dhabi, $U A E$. George received his PhD from King's College London, University of London, UK. Before joining HCT, George worked as an associate professor for King Abdulaziz University, Jeddah, Saudi Arabia for 8 years, teaching various undergraduate and postgraduate courses. Prior to joining academia, George worked for top tier financial institutions such as Bank of Ireland, Barclays Plc and London Stock Exchange via Accenture, UK. George also is a co-founder of Infosuccess3D, Athens, Greece an Interactive content development firm that has published several computer games, VR and AR applications. George has a significant research background with a plethora of funded projects and scientific publications including papers in top tier journals. George has delivered numerous webinars in well- known international institutions, organized multiple conferences and workshops. George has received a number of rewards, including best teacher, best applied research project as well as multiple rewards from various competitions.

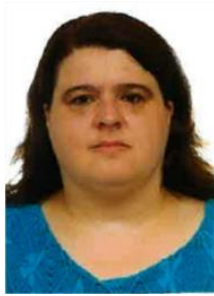

Athanasia Pavlopoulou is currently an Assistant Professor in Dokuz Eylül University (DEU), Department of Molecular Biology and Genetics, and group leader of the Computational Systems Biology laboratory in Izmir Biomedicine and Genome Center in Turkey (IBG). She has published more than 50 publications in peer-reviewed high profile ISI journals with more than 1300 citations and current h-index 19. Her main research interests include analysis of biological sequences, phylogenetics and comparative genomics, meta-analysis of epidemiological data, biological networks, analysis of high-throughput biological data, nutraceuticals, development of bioinformatics pipelines for the analysis of biological data. She has been involved in several big-budget research projects, both national and international.

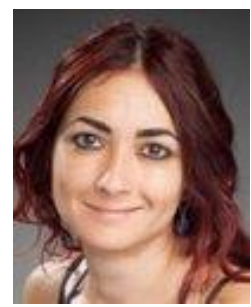

Zeynep Ahsen Koçer received her Bachelor's degree from the Department of Biological Sciences and her Master of Science degree from the Department of Biotechnology at the Institute of Natural and Applied Sciences at METU. She then completed her PhD in 2010 at the Department of Biological Sciences at Bowling Green State University in OH, USA. From July 2010 till Dec 2014, she pursued postdoctoral research with Dr. Robert Webster at the Virology Division of the Department of Infectious Diseases at St. Jude Children's Research Hospital in Memphis, TN; one of the six "WHO Collaborating Centers for Influenza" in the world and one of the six "Centers of Excellence for Influenza Research and Surveillance" funded by NIH NIAID. During her postdoctoral studies, she mainly worked on the pandemic potential of avian influenza viruses. Later, between Jan 2015-March 2017, she worked as a Staff Scientist at the Influenza Research Institute supervised by Prof. Dr. Yoshihiro Kawaoka at the University of Wisconsin-Madison. During that time, she mainly worked on the effect of genetic alterations in the polymerase complex of influenza A viruses on the zoonotic transmission of the virus, as well as their fidelity. Her projects were funded by CEIRS NIH/NIAID. She then returned to Turkey and started her current position in July 2017. Dr. Koçer is currently working as a Research Group Leader at the Emerging Viral Diseases Laboratory at IBG. Her research interests mainly focus on the 
emergence of novel zoonotic viruses and their risk assessment in terms of pandemic potential.

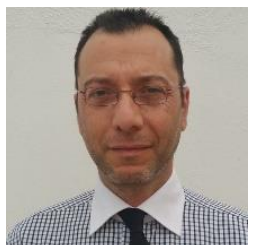

Dimitrios Piromalis is Assistant Professor in the Industrial Design and Production Engineering Department of University of West Attica (UNIWA). His research interests include the design and development of electronic embedded systems in application areas such as autonomous vehicles, internet of things, and cyber-physical systems. He is author of more than one hundred publications in international scientific research journals and conferences with high impact and many citations. Also, he is author of three books covering engineering subjects. Since 2020 he is the Director of the Research Laboratory of Electronic Automation, Telematics and Cyber-Physical Systems.

Publisher's Note: Engineered Science Publisher remains neutral with regard to jurisdictional claims in published maps and institutional affiliations. 